\title{
UN ALEGATO A FAVOR DE LAS CONSIDERACIONES PUNITIVAS EN EL DERECHO PRIVADO*
}

\author{
A PLEA FOR PUNITIVE CONSIDERATIONS IN PRIVATE LAW \\ UNE PLEDOIRIE À FAVEUR DES CONSIDÉRATIONS \\ PUNITIVES DANS LE DROIT PRIVÉ
}

Esteban Pereira Fredes**

\begin{abstract}
RESUMEN
A partir de una sentencia de la Corte de Apelaciones de Santiago, el artículo examina la tensión en que se encuentran nuestros tribunales de justicia, al indemnizar el daño moral en el ámbito de la responsabilidad extracontractual. Si bien rechazan que la indemnización decretada cumpla objetivos retributivos o disuasivos, ajustándose al principio de reparación integral del daño, en ciertos supuestos acuden a componentes punitivos en sus fallos, elevando el monto indemnizatorio. Se revisa esta tensión judicial, proponiendo su disolución a la luz de la pertinencia de consideraciones punitivas en el derecho privado.
\end{abstract}

Palabras Clave: Daños punitivos - Daños morales - Responsabilidad extracontractual Derecho privado

ABSTRACT

From a decision of the Court of Appeals of Santiago, the article examines the tension found in our courts of justice when they seek to compensate moral damages in the context of tort law. While they deny that these awards are aimed at retributive or deterrent objectives, sticking to the principle of full compensation for damage, in some cases they take into account punitive components in their judgments, raising the amount of the award. This legal tension is reviewed, proposing its dissolution by endorsing the appropriateness of punitive considerations in private law.

KEYWORDS: Punitive damages - Moral damages - Tort law - Private law

RÉSUMÉ

À partir d'un arrêt de la Cour d'appel de Santiago, cette chronique analyse la tension qu'on perçoit au sein de tribunaux de justice, lorsqu'il s'agit de l'indemnisation du dommage moral dans le domaine de la responsabilité délictuelle et quasidelictuelle. Même sills refusent que l'indemnisation accomplissent objetifs retributifs ou dissuasifs, conforme au principe de réparation integral du dommage, dans certains cas, on peut trouver un composant punitif dans leurs arrêts, en elevant le montant. On analyse cette tension judiciaire, en proposant sa disolusion à la lumière de la pertinence de considérations punitives dans le droit privé.

MOTS CLÉS: Dommages punitifs - Moral responsabilité - Délictuelle et quasi-delictuelle Droit privé

* Artículo recibido el 28 de abril de 2015 y aceptado para su publicación el 13 de junio de 2015 .

** Abogado. Licenciado en Ciencias Jurídicas y Sociales por la Universidad de Chile. Magíster en Derecho con Mención en Derecho Privado por la Universidad de Chile. Profesor Instructor en la Facultad de Derecho de la Universidad Adolfo Ibáñez. Correspondencia a: Correo electrónico esteban.pereira@uai.cl. Agradezco los valiosos comentarios que recibí de Alberto Pino Emhart sobre un borrador de este artículo. 


\section{INTRODUCCIÓN}

Una significativa tensión que está presente en las decisiones de nuestra jurisprudencia en materia de responsabilidad extracontractual, se identifica al momento de pronunciarse sobre la procedencia de daños punitivos en la indemnización de perjuicios a título de daños morales. Pese a que existen numerosas exigencias tanto legales como dogmáticas que sirven de vallas para su implementación en el derecho privado, los jueces se valen de consideraciones punitivas para justificar sus fallos. Lo revelador es que insisten en negar que ello sea así. Aun cuando es precisamente lo que se devela a partir de sus resoluciones. En tal sentido, la Ilustrísima Corte de Apelaciones de Rancagua, refiriéndose a un juicio sobre responsabilidad extracontractual en que se condenó a una tienda comercial cuyos guardias mantuvieron retenido injustamente a un cliente, golpeándolo y acusándolo erróneamente de robo, confirmó la sentencia de primera instancia, pero incrementó el monto de la indemnización de perjuicios por concepto de daño moral de $\$ 2.000 .000$.- a $\$ 15.000 .000 .-^{1}$.

$\mathrm{Al}$ respecto, la Corte dispuso lo siguiente:

"7.- [...] Un acto que afecta asi tanto la libertad como la honra, y que puede perjudicar tanto la salud física como la síquica de cualquier persona, es de una gravedad suficiente como para generar daños morales muy serios y profundos, que no se pueden satisfacer con una indemnización de dos millones de pesos. Es claro que la indemnización de que hablamos no tiene una naturaleza punitiva, y por ende no se trata de castigar ni la insolencia de los guardias, ni la pasividad de sus superiores, ni la mala fe de Ripley o Comercial Eccsa al dilatar la causa y pretender ocultarse en la maraña de nombres similares con que quiere protegerse; es igualmente cierto que la mayor capacidad económica del responsable, en sí misma y en principio, no debe influir en el monto que se conceda, porque lo que se valora es el daño causado, y no el poder del agresor o responsable. Pero todo ello es así salvo en cuanto tal poder o tales actitudes y dilaciones no hayan influido en la profundidad $y$ prolongación del mal" [Énfasis mio]².

El problema que buscan eludir nuestros órganos jurisdiccionales en este tipo de fallos radica en hacerse cargo de dos órdenes de consideraciones. De una parte, explicitar la aplicación de daños punitivos en nuestro esquema de responsabilidad civil extracontractual. Y, de otra, admitir que consideraciones retributivas o preventivas resultan pertinentes bajo nuestro sistema jurídico privado, desplazando la imagen tradicional de las reglas de responsabilidad extracontractual como reglas únicamente compensatorias vinculadas a exigencias de justicia correctiva. El presente artículo tiene por objetivo evaluar la aplicación de los daños punitivos en nuestra

${ }^{1}$ Corte de Apelaciones de Rancagua, “Arancibia More con Comercial Eccsa S.A.”, 1 de julio de 2013 (indemnización de perjuicios), rol N 1726-2012.

2 Este criterio es replicado en otras decisiones, como en Corte de Apelaciones de Concepción, "Sanhueza Vega con Vallejos Godoy”, 12 de marzo de 2013 (indemnización de perjuicios), rol No 1098-2012. 
práctica jurisprudencial, sugiriendo su pertinencia en el derecho privado, junto a la necesidad de atender a alegaciones punitivas como criterios para determinar el monto indemnizatorio del daño moral ${ }^{3}$.

Sostendré que el reconocimiento judicial de los daños punitivos no solo permitiría transparentar una significativa parte de los razonamientos y prácticas de nuestros tribunales de justicia, desplegados en sus decisiones sobre litigios de responsabilidad extracontractual, sino que además la admisión de consideraciones punitivas resulta razonable dado que estas proveen de razones legítimas para derrotar al principio de la reparación integral del daño. En efecto, se explorarán ciertas oportunidades en que la jurisprudencia también fractura las pretensiones de integridad del artículo 2329 del Código Civil, develando los límites y dificultades que la adopción incondicionada de este principio de reparación del daño podría acarrear. Tales exigencias, de orden retributivo y preventivo respecto a la conducta indeseada del autor del daño, permiten otorgar coherencia al régimen de responsabilidad extracontractual, ya que tanto criterios de justicia correctiva, como retributiva y distributiva han sido reconocidos como fines de la responsabilidad extracontractual ${ }^{4}$.

\section{Antecedentes del Caso}

La Corte de Apelaciones de Rancagua conoció un recurso de apelación deducido por Comercial Eccsa S.A., quien era la empresa administradora de la tienda Ripley en la ciudad de Rancagua. Ella había sido civilmente demandada por Francisco Arancibia More en atención a los daños que el indebido comportamiento de los guardias del local le habían ocasionado. Mientras Arancibia avanzaba por las escaleras del local, fue repentinamente atacado por un grupo de guardias. Estos lo lanzaron violentamente al suelo, procediendo a golpearlo, insultarlo y esposarlo. Así, el cliente fue conducido como detenido a una dependencia dentro del mismo recinto, sin que se acreditara haber siquiera formulado un cargo o efectuado una denuncia en su contra. El tribunal de primera instancia acogió la demanda de responsabilidad civil extracontractual por daños y perjuicios contra la sociedad,

\footnotetext{
${ }^{3}$ Para estudios focalizados en los daños punitivos bajo nuestra doctrina civil, pueden revisarse LARRAín PÁEz, Cristián (2008). "Aproximación a los Punitive Damages". En: Estudios de Derecho Civil IV. Jornadas Nacionales de Derecho Civil, Olmué, Pizarro Wilson, Carlos (Coord.), Santiago: LegalPublishing, pp. 707-719; y Segura Rivero, Francisco (2005). "Algunas consideraciones sobre la pena privada y los daños punitivos en el derecho civil chileno". En: Estudios de Derecho Civil. Jornadas Nacionales de Derecho Civil 2005-2009, Tomo IV, Varas Braun, Juan Andrés et al. (Coords.), Santiago: Abeledo Perrot, pp. 89-103.

${ }^{4}$ En este sentido, pero con una fuerte apuesta por la justicia correctiva, véase, BARROS BourIE, Enrique (2006). Tratado de Responsabilidad Extracontractual. Santiago: Editorial Jurídica de Chile, pp. 33-54. Una revisión de los objetivos de la responsabilidad extracontractual en ColEman, Jules L. (2010). Riesgos y Daños. Papayannis, Diego M. (Trad.), Madrid: Marcial Pons, pp. 205-218. Su reinterpretación en términos de una cuestión de justicia distributiva en PapaYannis, Diego M. (2014). Comprensión y Justificación de la Responsabilidad Extracontractual. Madrid: Marcial Pons, en especial, pp. 271-348.
} 
estableciendo su obligación de reparar los perjuicios sufridos por el actor. El monto de la indemnización a título de daño moral fue fijado en $\$ 2.000 .000$.-

La empresa alegó que el actor no había probado la efectiva vinculación entre Comercial Eccsa S.A. y la tienda Ripley, ya que en realidad esta última sería administrada por otra sociedad denominada "Ripley Store". De acuerdo a la demandada, la acción del actor carece de legitimación pasiva. Tampoco esgrimía suficientemente una acreditación de la relación causal existente entre los hechos cometidos por el personal y los daños sufridos por el señor Arancibia, como una consecuencia directa del trato recibido. La Corte desestimó ambas alegaciones. La primera solo buscaba eludir la responsabilidad de la demandada ocultando su unidad empresarial y, a su vez, la segunda era errónea, pues las vejaciones de que fue objeto el actor derivaban directamente de haber sido tratado como delincuente.

Por su parte, Arancibia More apeló esta resolución ya que estimó como insuficiente la cantidad indemnizatoria decretada judicialmente. La intensidad de sus lesiones inmateriales junto a la capacidad de la empresa para evitar y reparar todo yerro o daño que sus funcionarios pudieren cometer, motivaron su reclamo por un incremento en la indemnización del daño moral a la suma de \$15.000.000.-La Corte accedió a dicha petición, condenando a Comercial Eccsa S.A. en los siguientes términos:

"[...] El dolor de verse sometido a un vejamen también aumenta si la reparación demora injustamente, y todavía más si esa demora proviene, de nuevo, de quien no se espera; es decir, de una empresa que se supone seria, y que tiene capacidad para responder con prontitud, de lo que la ley le obliga a reparar. Es ese daño, asi aumentado, el que cabe valor aqui, y por todas esas razones -esto es, por las severas molestias, sufrimientos y dolores que el suceso innecesariamente prolongado en sus efectos ha causado al Sr. Arancibia More-la indemnización se regulará en la suma pedida en la demanda; es decir, en quince millones de pesos (\$15.000.000)".

De manera tal que se reprodujo la sentencia apelada, modificando la cifra final de la indemnización de los perjuicios morales. Esta cantidad debía ser reajustada y generaba intereses corrientes entre la fecha de la resolución y la de su pago efectivo. Tal decisión jurisdiccional no fue impugnada por Comercial Eccsa S.A., procediendo a cumplir con el pago del monto punitivamente aumentado por la Corte de Apelaciones. Ello reafirma el diagnóstico que inspira este trabajo; a saber, que no obstante la dogmática civil afirma sus reparos contra los daños punitivos y las consideraciones punitivas en el derecho privado, la jurisprudencia suele emplearlos en sus decisiones sobre juicios indemnizatorios, reclamando una resolución a esta tensión entre las exigencias legales y recomendaciones doctrinarias, de una parte, y las prácticas jurisprudenciales, de otra.

\section{DaÑos PUNITIVOS Y SU NEGACIÓN JURISPRUDENCIAL}

Veamos por qué la Corte de Apelaciones de Rancagua, tal como buena parte de nuestra jurisprudencia, decide aplicar instituciones cuya identidad es precisamente 
aquella que rechaza estar atendiendo en su resolución. Así, se afirma que el incremento en la indemnización de perjuicios morales que efectúa no responde a un carácter punitivo ni pretende castigar al autor del ilícito civil. Los daños punitivos corresponden a aquellos incrementos en el quantum indemnizatorio representado por la reparación del daño injustamente causado, cuyo exceso responde a consideraciones retributivas o preventivas, defraudando las expectativas del principio de reparación integral del daño 5 . Como se sabe, las reglas de responsabilidad civil extracontractual se ajustan al principio de la reparación integral del daño, contemplado en el artículo 2329 del Código Civil, según el cual todo daño causado a la víctima debe ser reparado. De igual modo, este opera como un límite a la reparación, dado que el alcance del quantum indemnizatorio no puede exceder al daño efectivamente ocasionado por el agente dañoso.

La reparación integral del daño se encuentra necesariamente en tensión con la aplicación judicial de los daños punitivos, porque si en una resolución operan daños punitivos se condena judicialmente al autor del hecho ilícito a pagar un monto de dinero superior a la cuantificación del daño, que en realidad ha sufrido la víctima. Desde un punto de vista normativo, la resolución judicial de la Corte no se ajusta a las exigencias de la reparación integral del daño, a lo menos, en la función de límite que este impone al juez. Sencillamente se fijó un monto superior a los perjuicios que se ocasionaron al cliente. De ahí que se ha sostenido en nuestra dogmática civil que este "[...] principio que gobierna la reparación de los daños obliga a desechar usos encubiertos de la misma como forma de castigo o sanción"6.

A su vez, desde una óptica sobre la fundamentación de las reglas sobre daños, la sentencia tampoco está conforme con la imagen del sistema de responsabilidad extracontractual, como un régimen de reglas jurídicas que atienden a consideraciones de justicia correctiva ${ }^{7}$. Tradicionalmente se ha pensado que la función de las reglas de responsabilidad extracontractual descansa en corregir el daño injustamente causado, de modo que las indemnizaciones de perjuicios únicamente deberían traducirse en una compensación de los perjuicios tanto patrimoniales como extrapatrimoniales generados en quien sufre la acción u omisión ilícita. La

\footnotetext{
${ }^{5}$ De acuerdo a Enrique Barros, los daños punitivos “[...] se refieren precisamente al monto de la indemnización que excede el perjuicio real sufrido por la víctima”. Barros Bourie (2006), p. 218, n. 7. Asimismo, se ha entendido que se trata de "[...] sumas de dinero que los tribunales mandan a pagar a la víctima de ciertos ilícitos, que se suman a las indemnizaciones por daños realmente experimentados por el damnificado, que están destinados a punir graves inconductas del demandado y a prevenir hechos similares en el futuro”. Pizarro, Ramón Daniel (1996). Daño moral. Prevención. Reparación. Punición. El daño moral en las diversas ramas del Derecho. Buenos Aires: Hammurabi, p. 374.

${ }^{6}$ Domínguez Hidalgo, Carmen (2008). "Los derechos de la personalidad y el principio de reparación integral del daño". En: Estudios de Derecho Civil IV. Jornadas Nacionales de Derecho Civil, Olmué, Pizarro WiLson, Carlos (Coord.), Santiago: LegalPublishing, p. 658.

7 Para una versión paradigmática en este sentido, véase WeInRIB, Ernest J. (2012). The Idea of Private Law. Oxford: Oxford University Press, 2a Edición revisada, pp. 56-83.
} 
pertinencia de los daños punitivos supone que dicha imagen es solo parcial, pues las reglas de daños también incorporan dimensiones retributivas o disuasivas de conductas socialmente indeseadas ${ }^{8}$.

Ambos niveles de análisis resultan problemáticos en la decisión de la Corte y ello explica en parte por qué nuestro tribunal se esfuerza en afirmar que la indemnización decretada no tiene una naturaleza punitiva ni responde a un propósito de castigar al civilmente responsable del daño. No obstante lo cual, en su práctica judicial, ella determina el aumento del monto indemnizatorio formulado en la primera instancia, atendiendo a la gravedad de los hechos que afectaron a la víctima y, por consiguiente, defraudando al artículo 2329 del Código de Bello. Su eventual reconocimiento relativo a la procedencia del daño punitivo en su resolución implicaría asumir ambos órdenes de observaciones anotados más arriba; a saber, que dado que junto a consideraciones de justicia correctiva conviven exigencias de justicia retributiva, corresponde incrementar el quantum indemnizatorio más allá de la cantidad correspondiente a la reparación del daño, cuando a la luz de la gravedad de los hechos develada por la conducta del agente dañoso, procede castigarlo económicamente, desafiando al principio de integridad que rige la reparación de los daños extracontractuales. Según se puede desprender de su declaración, el rechazo a tales consideraciones explica cómo la Corte niega explícitamente aquello que decreta jurisdiccionalmente. De ahí su insistencia en sostener que " $[e]$ s claro que la indemnización de que hablamos no tiene una naturaleza punitiva, y por ende no se trata de castigar [...]".

\section{UNA PRÁCTICA JUDICIAL DEVELADA}

La tensión que apreciamos en el razonamiento de la Corte puede admitirse como un lugar común en nuestras prácticas judiciales, cuando se trata de determinar la operatividad de los daños punitivos en materia de indemnización de perjuicios morales 9 . Suelen aplicarse los daños punitivos y, de igual manera, es negado el carácter punitivo de la indemnización de perjuicios que se decreta. Pues bien, ¿̨cómo podemos otorgar consistencia a esta práctica judicial? Desde luego, una solución de lege ferenda sería la formulación de una legislación que introdujese la institución de los daños punitivos, tal como la experiencia comparada lo ha sugerido. Por ejem-

\footnotetext{
${ }^{8}$ Un sumario de las funciones de los daños punitivos en Coderch, Pablo Salvador y Castiñeira Palou, María Teresa (1997). Prevenir y Castigar. Libertad de información, expresión, tutela del honor y funciones del derecho de daños. Madrid: Marcial Pons, pp. 165-166. Acerca de la disuasión como propósito en el derecho privado, véase, TAN, Yock Lin (2009). "Deterrence in Private Law". En: The Goals of Private Law, RoBERTSON, Andrew y TANG, Hang Wu (Eds.), Oxford \& Portland: Hart Publishing, pp. 311-339.

9 Si bien las reglas de responsabilidad extracontractual encarnan un compromiso con fines reparatorios o compensatorios del daño generado, como lo advierte con acierto BARROs, "[...] en la práctica jurisprudencial y en la doctrina legal, algún sesgo punitivo suele aparecer cuando se trata de valorar el daño moral”. BARRos Bourie (2006), p. 218, n. 9.
} 
plo, en el marco de la reforma a la Ley de Defensa del Consumidor en Argentina, verificada en el año 2008 y que se tradujo en el artículo 52 bis, en virtud de la cual, respecto del proveedor que no cumpla sus obligaciones con el consumidor, el juez podrá aplicar una multa civil a favor del consumidor, en atención a la gravedad de los hechos y demás antecedentes relevantes ${ }^{10}$.

Sin embargo, esta solución sería apresurada. Ya sabemos de las gruesas dificultades que ha enfrentado el establecimiento legislativo de los daños punitivos tanto en el common law como en el contexto continental ${ }^{11}$. Además, los esfuerzos legislativos han versado sobre áreas específicas de producción de daños, como ocurre con el ámbito del derecho del consumidor, donde las asimetrías económicas entre el autor del daño y sus víctimas justifican la aplicación de multas civiles que disuadan a los proveedores de dañar a sus consumidores ${ }^{12}$.

Un camino quizás bastante más fértil radica en esgrimir razones que justifiquen una decisión judicial como la articulada por la Corte de Apelaciones de Rancagua, evitando que el órgano jurisdiccional se vea forzado a negar en su sentencia lo que conceptualmente ahí implementa. El límite estándar a los daños punitivos se encuentra en el principio de reparación integral de los daños, de modo que corresponde entenderlos como una fractura al artículo 2329 del Código Civil. El problema es que dicho principio no está exento de tensiones. Normalmente nuestra judicatura efectúa otras transgresiones a la integridad reparatoria, precisamente en sus decisiones judiciales sobre daños extracontractuales. Permítaseme evidenciar solo dos de ellas. Dado que el daño moral presenta un inevitable desafío para los tribunales al momento de su determinación, la reconstrucción de las decisiones judiciales sobre la reparación de daños morales ha reemplazado su subjetividad y déficit de cuantificación, por el establecimiento de criterios que son adoptados por nuestros jueces para determinar el quantum indemnizatorio de daños no

\footnotetext{
${ }^{10}$ Conviene tener presente que la Ley de Protección sobre los Derechos de los Consumidores, ley Nº 19.496, enfrenta actualmente un proceso de discusión legislativa asociado, entre otros puntos, a la modificación de su artículo 53 C, introduciendo la figura de los daños punitivos. En el Mensaje $\mathrm{N}^{\circ} 141-362$, de 2 de junio de 2014, se propuso agregar la siguiente frase: "En aquellos casos de reincidencia conforme al inciso tercero del artículo 24, y cuando el tribunal en su sentencia declare que la infracción ha producido un riesgo elevado para los consumidores, podrá aumentar en un 25\% la indemnización determinada en la sentencia”.

11 Para sistematizaciones sobre las vallas que debe sortear la introducción de los daños punitivos en el sistema jurídico privado, véanse Barros Bourie (2006), pp. 304-310; Pizarro (1996), pp. 383-390. Con un énfasis en los problemas de constitucionalidad y legalidad, Gómez Tomillo, Manuel (2013). "Los daños punitivos: Análisis desde una perspectiva jurídico-penal. Al mismo tiempo reflexión sobre garantías en fenómenos materialmente sancionatorios". En: Limites entre el Derecho Sancionador y el Derecho Privado: Daños Punitivos, comiso y responsabilidad patrimonial derivada de infracciones administrativas, GómEZ Tomillo, Manuel (Ed.), Madrid: Lex Nova, pp. 33-51.

${ }^{12}$ Con todo, no existe un entendimiento uniforme de los daños punitivos, sino que los distintos ordenamientos jurídicos consagran una diversidad de figuras dotadas de características disímiles. Esta diversidad de manifestaciones agudiza las dudas sobre la conveniencia de consagrar legislativamente a los daños punitivos. Al respecto, véase, De Ángel Yágưez, Ricardo (2012). Daños Punitivos. Madrid: Civitas, pp. 13-40.
} 
patrimoniales, aun cuando no se encuentren consagrados en el título XXXV del Código Civil.

Uno de ellos es la gravedad de los hechos, la cual se transparenta en la comisión dolosa del hecho ilícito por parte del autor del daño. En este sentido, la Corte declaró que "[u]n acto que afecta asi tanto la libertad como la honra, y que puede perjudicar tanto la salud física como la síquica de cualquier persona, es de una gravedad suficiente como para generar daños morales muy serios y profundos, que no se pueden satisfacer con una indemnización de dos millones de pesos". Ello justifica, según el prisma jurisdiccional, el incremento del monto indemnizatorio a $\$ 15.000 .000$.Ahora bien, es cierto que para el éxito de una acción de responsabilidad extracontractual, de acuerdo al artículo 2314, resulta irrelevante que la infracción al deber de cuidado se haya verificado con culpa o dolo, pero efectivamente existen ciertos matices en esta indiferencia legislativa. Cuando se encuentra presente el dolo en la lesión de los intereses de la víctima, el juez incrementa el monto de la indemnización de perjuicios, excediendo el estimado para la mera reparación de los daños ocasionados ${ }^{13}$. El dolo es un indicio de gravedad en la conducta del agente dañoso y de ahí que no resultan suficientes las consideraciones correctivas de la reparación integral, dando cabida a las exigencias retributivas o disuasivas cubiertas por los daños punitivos.

Por otra parte, no solo la gravedad del comportamiento del agresor es decisiva para que un tribunal desafíe lo dispuesto en el artículo 2329, sino también la situación económica del autor del daño posibilita el aumento del quantum indemnizatorio a favor de su víctima. Existe una relación proporcional entre los medios económicos con que cuenta el agente dañoso y las sumas de dinero a cuyo pago es judicialmente condenado ${ }^{14}$. Las facultades económicas del demandado son cruciales para la determinación de montos indemnizatorios elevados, forjando la noción de deep pocket en el derecho de daños ${ }^{15}$. De nuevo es posible evidenciar la tensión que experimenta la Corte, al justificar el incremento en la cantidad establecida por el tribunal a quo. Su razonamiento sigue los lineamientos canónicos de la reparación integral del derecho, sin embargo, con posterioridad atenúa sus exigencias tomando

\footnotetext{
${ }^{13}$ En este sentido, véase Barros Bourie (2006), pp. 166-167. Según sus palabras, [...] aunque la indemnización tiene por naturaleza un fin reparador, la apreciación del daño moral incorpora aspectos punitivos, como se muestra en la consideración explícita o implícita que los fallos realizan de la gravedad de culpa. En tal sentido, el dolo y la culpa, e incluso la intensidad de esta última, suelen ser determinantes al momento de valorar el daño moral". Barros Bourie (2006), p. 167. Este razonamiento también puede encontrarse en Corte de Apelaciones de Rancagua, "Juacida Percaz con Pizarro Letelier", 19 de mayo de 2014 (indemnización de perjuicios), rol No 1119-2013.

${ }^{14}$ De igual manera, en Corte de Apelaciones de Talca, "Warnken Díaz con Fisco de Chile", 10 de enero de 2010 (indemnización de perjuicios), rol N 1356-2008.

15 Acerca de la implementación de los daños punitivos como un mecanismo para defender la libre competencia, puede consultarse BANFI DEL Río, Cristián (2013). "La responsabilidad civil como forma de aplicación privada del derecho de la competencia”. Revista Chilena de Derecho Privado, № 21, pp. 225-231.
} 
atención de los altos recursos y medios económicos de Comercial Eccsa S.A., en su calidad de administradora de la tienda Ripley. El tránsito entre ambas dimensiones de análisis se transparenta en el siguiente extracto del considerando tercero:

"[...] es igualmente cierto que la mayor capacidad económica del responsable, en sí misma $y$ en principio, no debe influir en el monto que se conceda, porque lo que se valora es el daño causado, y no el poder del agresor o responsable. Pero todo ello es asi salvo en cuanto tal poder o tales actitudes y dilaciones no hayan influido en la profundidad y prolongación del mal. Porque es también claro que el sufrimiento causado se agrava cuando se dilata la reparación injustamente, sin haberse efectuado jamás un intento para morigerar los efectos del hecho ilícito, y todavía más cuando quien lo causa o quien disponia del mando sobre el hechor, y elude su responsabilidad prolongando el mal, es una empresa que por su magnitud, capacidad y publicidad, debiera ser prioritaria cumplidora de sus obligaciones de respeto al público, de control de sus empleados y agentes, y de reparación de los errores o abusos que en su dependencias se cometan".

\section{DERECHO PRIVADO, DAÑOS PUNITIVOS Y LA DISOLUCIÓN DE LA TENSIÓN}

De acuerdo a lo anteriormente señalado, en la práctica jurisprudencial tienen lugar fracturas al principio de reparación integral del daño extracontractual, adicionales a la admisión de los daños punitivos en nuestro sistema jurídico privado. Acá tenemos razones que revelan la insuficiencia del artículo 2329, ayudando a disolver la tensión en que se encuentra el órgano jurisdiccional ${ }^{16}$. El problema no es tanto que esta regla legal sea incorrecta o que las pérdidas generadas por el ilícito no se compensen, como que en estos supuestos el ideal de la corrección o compensación es insuficiente para reparar el mal causado. Ya sea por la gravedad de la conducta, la presencia de facultades económicas sustantivas del demandado o una decisión con cargo a objetivos disuasivos, la indemnización compensatoria no es suficiente. De ahí la pertinencia del daño punitivo. Por supuesto, se podría sostener que la aplicación práctica de estos criterios jurisprudenciales en la determinación del monto de la indemnización de perjuicios, nada dice genuinamente relevante sobre su razonabilidad. Es decir, los jueces pudieren atender a razones erróneas cuando transgreden la reparación integral del daño por la gravedad de los hechos, así como al considerar la capacidad patrimonial del agente dañoso,

\footnotetext{
${ }^{16}$ Es revelador que tanto la gravedad de la conducta del agente dañoso como sus facultades económicas, constituyen criterios que están en alta consonancia con consideraciones punitivas en la indemnización extracontractual. Resulta necesario detenerse en ellos, ya que arrojan luz sobre las fisuras existentes en el principio de la reparación integral del daño. Bajo sus exigencias, ambas no debieren ser tomadas en cuenta por el órgano jurisdiccional. Como lo sugiere Domínguez, "[...] si se afirma que la responsabilidad civil sólo tiene por función reparar el daño causado y, por ende, sólo ha de concentrarse en lo que el perjuicio importa o ha importado para la víctima, mal puede atenderse - para ningún efecto- a la conducta tenida por el responsable, esto a su gravedad o la fortuna del mismo como erradamente se invoca en algunas decisiones judiciales". Véase, Domínguez Hidalgo (2008), p. 658.
} 
elevando el quantum indemnizatorio. Tal cuestión hay que evaluarla a partir de un argumento normativo cuyo rendimiento explicativo es indispensable en la discusión sobre los daños punitivos. El artículo 1558 del Código Civil pudiere proporcionar contribuciones sustantivas en tal sentido ${ }^{17}$.

Según sabemos, esta regla jurídica establece una relación entre el factor del incumplimiento contractual y los daños que correlativamente debe reparar el deudor. Nuestro codificador reconoció en el incumplimiento contractual doloso una razón legítima para amplificar la carga reparatoria de los perjuicios, debiendo tal deudor responder de los perjuicios directos, tanto previstos como imprevistos. A su vez, si la observancia del vínculo contractual se debe a la culpa del deudor, este únicamente responderá de los perjuicios directos previstos. La justificación de esta regla se sigue de la sanción del dolo que se encuentra presente en el texto civil, porque implica una infracción de la buena fe, entendida como un principio general del derecho privado. Pero, de igual forma, de ella subyacen consideraciones retributivas que están presentes en la formulación de la regla, bajo las cuales resulta válido castigar civilmente al deudor que haya inferido perjuicios contractuales al acreedor, si su infracción fue ocasionada con la intención de provocar daño. La gravedad del comportamiento permite incrementar el grupo de perjuicios de los que debe responder patrimonialmente el deudor, aun cuando los daños imprevistos no sean necesariamente daños que debieren repararse, porque exceden los daños que debieron o pudieron preverse al momento de la celebración del contrato.

¿Qué nos sugiere este fundamento normativo? Para nuestro sistema de responsabilidad civil el dolo constituye un indicador de la gravedad de la conducta de quien causa el daño, autorizando la ampliación de los perjuicios de que debe responder ${ }^{18}$. En ocasiones, el juez se encuentra facultado para condenar civilmente al deudor por perjuicios mayores a los que correspondería a una simple compensación. Esta consideración no fue desconocida para Bello y, si parte de la dogmática civil contemporánea está en lo cierto, la ubicación del artículo 1558 en materia contractual no es un argumento decisivo para descartar su aplicación en sede extracontractual ${ }^{19}$. El estándar de comportamiento exigido entre las partes de un vínculo previo así

\footnotetext{
${ }^{17}$ La relevancia del tratamiento del dolo en el artículo 1558 del Código Civil en nuestra comprensión de la responsabilidad civil extracontractual, ha sido puesta de manifiesto en BANFI DEL Río, Cristián (2012). "Por una reparación integral del daño extracontractual limitada a los hechos dolosos o gravemente negligentes". Ius et Praxis, Vol. 18, $\mathrm{N}^{\circ} 2$, pp. 3-32.

18 Según Banfi, la mayor reprobación de la conducta sugiere introducir un elemento punitivo en la responsabilidad extracontractual, "[...] que si bien choca con la función resarcitoria que la doctrina civilista nacional generalmente concede a la responsabilidad civil, es un corolario de la naturaleza e importancia del dolo". BANFi del Río (2012), p. 6.

19 La operatividad de la regla del artículo 1558 tanto en el régimen de responsabilidad contractual como extracontractual es sostenida en BArros Bourie (2006), pp. 164-166 y BANFi Del Río (2012), pp. 3-32. Conviene recordar que la extensión de reglas situadas en el ámbito contractual al sistema extracontractual, también se ha producido respecto del artículo 1556 del Código Civil. Sobre esta regla legal no hay dudas de su aplicación en ambos sistema de responsabilidad.
} 
como entre extraños, corresponde a un nivel de hombre medio y juicioso, del cual es genéricamente razonable exigir su responsabilidad por culpa leve, tanto en sus relaciones contractuales como aquellas suscitadas al margen del contrato.

Esta regla legal permitiría otorgar consistencia interna al sistema de responsabilidad civil vigente entre nosotros, reconociendo que en el dolo encontramos un factor que no resultó indiferente para nuestro codificador, sino que justifica un incremento del quantum indemnizatorio. Del mismo modo, en que el incumplimiento contractual doloso sugiere la consideración a daños que no fueron previstos por el deudor, la infracción dolosa a los deberes de cuidado que nos debemos recíprocamente, justificaría la pertinencia de daños punitivos que en atención a la gravedad reflejada en el comportamiento del agente, fracturan legítimamente al principio de reparación del daño extracontractual. Sin necesidad de formular una legislación distinta a la que heredamos, los esfuerzos interpretativos se pueden reconducir hacia las prácticas jurisprudenciales en que se alteran las exigencias del artículo 2329 y, en especial, a determinar el alcance del artículo 1558 en el régimen de responsabilidad civil, autorizando el incremento del monto de la indemnización de perjuicios cuando el daño sea cometido dolosamente. Por lo demás, tal regla no hace sino consagrar la práctica judicial que antes analizamos respecto del daño moral y que también develaba una fisura en la reparación íntegra del daño extracontractual.

Una forma de robustecer esta línea argumentativa pudiere encontrarse en el inciso final del artículo 23 de la ley No 19.628, sobre protección de la vida privada. De acuerdo a esta regla, la persona natural o jurídica que produjere daños patrimoniales o morales por un tratamiento indebido de los datos deberá indemnizarlos, y este monto "será establecido prudencialmente por el juez, considerando las circunstancias del caso y la gravedad de los hechos". Nuevamente, nos encontramos con la consideración acerca de la gravedad de la conducta del agente que ocasiona el daño para decidir el quantum indemnizatorio. Desde luego, el comportamiento doloso en el manejo de los datos personales conllevará el incremento en la suma de dinero a la cual se le condenará. De ahí que cobran fuerza las dimensiones punitivas de la indemnización de perjuicios. De modo tal que sistemáticamente también forma parte de nuestro sistema jurídico, una legislación especial que consagra la operatividad de los daños punitivos ${ }^{20}$.

Como se puede apreciar, resta referirse al derecho privado. Después de todo, la reticencia jurisdiccional para reconocer que se atiende a las consideraciones punitivas que son explícitamente negadas, se explica porque la introducción de alegaciones punitivas en el derecho privado conlleva enfrentar cuestiones de segun-

\footnotetext{
${ }^{20}$ En relación a los estándares que debe considerar el juez para fijar el monto de la indemnización, se ha afirmado que " $[s]$ e observa aquí la función punitiva que, aun en nuestro régimen sigue manteniéndose, si bien en forma soterrada”. Véase, Corral TALCIANI, Hernán (2013). Lecciones de Responsabilidad Extracontractual. Santiago: Thomson Reuters, 2a Edición actualizada, p. 283.
} 
do orden. En último término, esto involucra preguntarnos qué debemos entender por derecho privado y cuáles son las funciones del sistema de responsabilidad extracontractual. Ambas preocupaciones sugieren que el sistema jurídico privado en general $y$, asimismo, las reglas de responsabilidad extracontractual en particular, pudieren responder a consideraciones distintas a las provistas por la justicia correctiva $^{21}$. La pertinencia de finalidades punitivas en el ámbito de la responsabilidad civil muestra que la complejidad del derecho privado no puede interpretarse solo a partir de los parámetros de la corrección. Ello explica la precaución de la Corte de Apelaciones de Rancagua, invitándonos a tomar nota de que "[e]s claro que la indemnización de que hablamos no tiene una naturaleza punitiva, y por ende no se trata de castigar". No obstante, y según lo revisamos, invoca criterios retributivos para justificar su decisión de incrementar el monto indemnizatorio del daño moral a favor del señor Arancibia.

Desde luego, la Corte no ofreció un entendimiento acerca del derecho privado, pero sí entregó pistas sobre la función que, a su juicio, desempeñan las reglas de responsabilidad extracontractual. Pese a que haya terminado por contradecirla en la resolución judicial. Su óptica descansa en la tesis según la cual las reglas de responsabilidad extracontractual persiguen reparar el daño causado, apelando a las exigencias estándar de la justicia correctiva. ¿Es suficiente interpretar al derecho de daños solo en estos términos? Ciertamente es discutible. Cristián BANFI ha sugerido que la apelación al dolo en la responsabilidad extracontractual para determinar el vínculo causal y la mayor extensión en la reparación de los perjuicios implica introducir un factor punitivo en este ámbito de la responsabilidad civil. Incluso sin propiciar directamente la introducción de daños punitivos, piensa el autor, que es conveniente "[...] recalcar que la responsabilidad civil es también un instrumento que atiende un fin retributivo en la medida que la indemnización encierra todos los daños que proceden directa y necesariamente del hecho ilícito doloso o gravemente descuidado" 22 .

De la discusión sobre las funciones de la responsabilidad extracontractual subyacen comprensiones rivales acerca de lo que es el derecho privado y cuáles

\footnotetext{
${ }^{21}$ En especial, esto acarrea significativos problemas de conciliación bajo el sistema jurídico anglosajón. Según WeinRib, “[...] bajo la justicia correctiva los daños son compensatorios, no punitivos. Por lo tanto, la jurisdicción del common law cuya actitud respecto a los daños punitivos se acerca más a la conformidad a la justicia correctiva es Inglaterra”. WeInRIB (2012), p. 135, n. 25. Ahora bien, de acuerdo a Allan BeEver, el contraste entre los daños agravados y los daños ejemplares en términos de su estructura, permite explorar que los daños agravados poseen un sólido fundamento compensatorio en el derecho privado. Los daños ejemplares (equivalentes a los daños punitivos), en cambio, debieren ser abolidos ya que se encuentran en grave tensión con la naturaleza de la responsabilidad civil. Véase, BeEver, Allan (2003). "The Structure of Aggravated and Exemplary Damages”. Oxford Journal of Legal Studies, Vol. 23, N 1, pp. 87-110.

22 BANFi del Río (2012), p. 6.
} 
son sus propósitos ${ }^{23}$. Si se admite que en el sistema jurídico privado hay exigencias distintas a las formuladas por justicia correctiva, entonces, es posible otorgar consistencia a la práctica jurisprudencial que hemos revisado gracias a la decisión de la Corte. Apelar a consideraciones punitivas en el derecho privado es judicialmente pertinente, porque no solo contamos con reglas jurídicas que responden a estos ribetes justificativos, sino que además no hay razones excluyentes para renunciar a un entendimiento sobre el derecho privado que las incluya. Así, la Corte de Apelaciones de Rancagua, como los restantes órganos jurisdiccionales, no se verá en aprietos al negar lingüísticamente lo que judicialmente realiza.

$\mathrm{Al}$ respecto, es interesante centrar nuestra atención en la conexión existente entre las reglas penales y las reglas de la responsabilidad extracontractual. Este vínculo sostenido en los estudios de teoría del derecho, no ha sido aprovechado del todo por los estudios dogmáticos en derecho civil ${ }^{24}$. En la teoría jurídica analítica de la segunda mitad del siglo XX, H.L.A. HART indicó que un sistema jurídico propiamente tal debía conformarse de dos tipos de reglas jurídicas: reglas primarias y reglas secundarias. Mientras las primeras se ajustan a un modelo de órdenes que imponen obligaciones, mediante la amenaza de sanciones correlativas a su transgresión, las segundas cumplen una función social totalmente diversa, es decir, otorgar facilidades para que los individuos materialicen sus planes personales de vida. Sin embargo, el autor advirtió con razón la existencia de una cierta analogía, que media "[...] entre tales órdenes generales y las normas que regulan la responsabilidad extracontractual" 25 . Bajo el contexto del derecho de daños también existen reglas jurídicas que fijan conductas calificadas de ilícitos civiles, imponiendo a sus destinatarios la obligación de abstenerse de su verificación. De acuerdo a HART, a la infracción de un deber general de cuidado que nos debemos recíprocamente en nuestros encuentros espontáneos “[...] se le denomina 'violación de un deber' y a la indemnización de perjuicios u otros remedios jurídicos, 'sanción'”26.

Una lectura posible de la aproximación hartiana es que las reglas primarias del fenómeno jurídico no son las reglas del derecho penal. Su estructura es más bien genérica, incluyendo a las diversas reglas jurídicas que cumplen la función de disuadir comportamientos indeseados por el derecho e impongan sanciones frente a su comisión. Las reglas de la responsabilidad extracontractual satisfacen ambos

${ }^{23}$ Esta estrategia es evidente en el programa de investigación esgrimido por el internalismo en la filosofía del derecho privado. Al respecto, véase WeInRIB (2012), pp. ix-xx; 1-21.

${ }^{24}$ Acerca de la relación entre las reglas del derecho de daños y las reglas del derecho penal, bajo la estructura de las reglas primarias diseñada por Hart, véase Pereira Fredes, Esteban (2014). "Reglas primarias y teoría analítica del derecho". En: Hart en la Teoría del Derecho Contemporánea: A 50 años de El Concepto de Derecho, Figueroa Rubio, Sebastián (Ed.), Santiago: Ediciones Universidad Diego Portales, pp. 391-402.

${ }^{25}$ Hart, H.L.A. (1963). El Concepto de Derecho [The Concept of Law]. Carrió, Genaro R. (Trad.), Buenos Aires: Abeledo Perrot, p. 35.

${ }^{26}$ HART (1963), p. 35. 
parámetros, aun cuando lo hagan con una intensidad indudablemente menor que las reglas jurídico-penales ${ }^{27}$. Ello podría transparentar la asociación que rige entre ambos tipos de reglas, evitando lo tosco que resulta escindir entre las reglas del derecho penal y las pertenecientes al derecho privado. Por ello, HART construyó su contraste entre las reglas que imponen deberes y obligaciones y aquellas que cumplen una función social radicalmente distinta, acordando a los particulares "[...] facilidades para llevar a cabo sus deseos, al otorgarles potestades para crear [...] estructuras de facultades y deberes dentro del cuadro coercitivo del derecho" 28 .

No debemos desatender el hecho de que esta relación ha sido advertida en la filosofía del derecho privado contemporáneo. A nivel de cuestiones tanto de identidad como normativas, el derecho de la responsabilidad extracontractual y el derecho penal comparten ciertos rasgos comunes. Tony Honoré ha observado que "[c]ada uno apunta a eliminar o reducir comportamientos indeseables, cada uno contempla sanciones a ser impuestas sobre aquellos cuya conducta es indeseable, y cada uno plantea interrogantes complejas acerca de las condiciones para imponer sanciones y el grado de responsabilidad de los autores de los actos ilícitos" ${ }^{29}$. Después de todo, las reglas jurídicas pertenecientes a ambas parcelas de lo jurídico, parecen responder a la taxonomía genérica de reglas que imponen deberes u obligaciones y, por consiguiente, se ajustarían prima facie a la estructura primaria de reglas hartiana.

En estos términos, es posible contribuir a disolver la tensión que aquejó a la Corte al negar la presencia de componentes punitivos en la responsabilidad extracontractual, pese a acudir a este espectro de consideraciones en la justificación de su aumento del monto indemnizatorio. Un derecho privado robusto exige conjugar la pertinencia de alegaciones retributivas o preventivas en sus reglas jurídicas y prácticas jurisprudenciales. Bajo un enfoque articulado en tales coordenadas, la tensión judicial pierde su genuina justificación. Al transparentar la práctica jurisprudencial en materia de determinación del monto de la indemnización de daños morales, únicamente hacemos hincapié en lo que es el derecho privado,

\footnotetext{
${ }^{27}$ Esto ha sido correctamente enfatizado por John C.P. Goldberg y Benjamin C. ZipursKY. Al declarar como civilmente responsables a los demandados, estos deben rendir cuentas por el ilícito que han hecho. Si bien solo deberán pagar indemnizaciones compensatorias, ello cumple un rol sancionatorio. Al respecto, véase, Goldberg, John C.P. y Zipursky, Benjamin C. (2014). “Tort Law and Responsibility”. En: Philosophical Foundations of the Law of Torts, OBERDiEK, John (Ed.), Oxford: Oxford University Press, pp. 17-37. A su vez, Peter BirKs destaca que una indemnización de perjuicios puede ser considerada en términos de un castigo. En sus palabras, "[l] os daños compensatorios corren fácilmente en cientos de miles de libras, incluso sin la adición de un daño agravado, y mucho menos un elemento punitivo". Bırks, Peter (1992). "Civil Wrongs: A New World". En: Buttersworths Lectures 1990-1991, London: Buttersworths, p. 80.

${ }^{28}$ HaRT (1963), p. 35. Cursivas mías.

${ }^{29}$ Honoré, Tony (1999). Responsibility and Fault. Oxford \& Portland: Hart Publishing, p. 68.
} 
apelando a una de las funciones que la responsabilidad extracontractual puede satisfactoriamente proveer $^{30}$.

Por supuesto, se podrá objetar que el valor explicativo de esta propuesta depende de una relación analítica entre las consideraciones punitivas y los daños punitivos bajo el sistema jurídico privado ${ }^{31}$. En otras palabras, que de la presencia de alegaciones extraídas del primer ámbito se sigue necesariamente el reconocimiento de los daños punitivos en la responsabilidad extracontractual. Considero que efectivamente no es así. Ambas cuestiones tienen una relación contingente entre sí, pero en sede de responsabilidad extracontractual la pertinencia de justificaciones retributivas o preventivas desencadena la aplicación de daños punitivos en la fijación del quantum indemnizatorio de los daños morales ${ }^{32}$. El sentido de la tensión judicial entre negar y aplicar componentes punitivos, radica en la creencia bajo la cual dado que el derecho de responsabilidad extracontractual únicamente persigue objetivos reparatorios, entonces, la indemnización de perjuicios no puede poseer un carácter punitivo.

Si lo anterior fuere correcto, la tensión que originalmente apreciamos en la declaración judicial de la Corte de Apelaciones de Rancagua, devela las dificultades que experimentan nuestros jueces para reconocer la implementación de consideraciones retributivas o preventivas, al sancionar civilmente a comportamientos graves que provocan daños ${ }^{33}$. El principio de reparación integral del daño constituye un disuasivo formidable que insta a los tribunales a afirmar que, en atención a exigencias correctivas, solo reparan los daños extracontractuales efectivamente causados, en circunstancias de que entre sus consideraciones también conviven criterios punitivos. Los daños punitivos no deben pensarse únicamente a partir de una reforma legislativa, pues las prácticas judiciales transparentan su vigencia y, a su vez, el artículo 1558 permite la construcción de su fundamento normativo.

\footnotetext{
${ }^{30}$ La conciliación entre la imagen compensatoria de la responsabilidad extracontractual y las directrices de la justicia distributiva, está convincentemente articulada en PINO-EMHART, Alberto (2013). "Entre reparación y distribución: La responsabilidad civil extracontractual como mecanismo de distribución de infortunios". Revista Chilena de Derecho Privado, No 21, pp. 89-135.

31 La postura de BANFI, por su parte, defiende la idea según la cual la reparación integral de los daños directos debe quedar circunscrita a los hechos dolosos o gravemente negligentes del agente dañoso, con independencia de la introducción de los daños punitivos en la responsabilidad extracontractual. Por consiguiente, su esfuerzo interpretativo constituye una justificación de los propósitos retributivos que suscribe la responsabilidad extracontractual, sin necesidad de sostener por ello el ingreso de los daños punitivos.

32 Con todo, el fundamento de los daños punitivos también es objeto de controversia. Si bien he acudido indistintamente a la retribución y disuasión como fines de estas indemnizaciones, cada uno de los propósitos puede esgrimirse para justificar su procedencia. En tal sentido, el punto de vista retributivo está defendido en Sевок, Anthony J. (2007). "Punitive Damages: From Myth to Theory". Iowa Law Review, $\mathrm{N}^{\circ}$ 92, pp. 957-1036. El prisma disuasivo, por su parte, es articulado en Edelman, James (2009). "In Defence of Exemplary Damages”. Justifying Private Law Remedies, RicketT, Charles E.F. (Ed.), Oxford: Hart Publishing, pp. 226-248.

${ }^{33}$ Sobre la función preventiva del derecho de daños, véase, Coderch y Castiñeira Palou (1997), pp. 117-124.
} 
La jurisprudencia no debiere esperar a una innovación legal para evitar reconocer aquello que está efectuando en su sentencia cuando decreta el incremento del monto en la indemnización de daños morales, pues nuestro sistema de responsabilidad extracontractual es lo suficientemente generoso para ayudarle a disolver aquella tensión.

\section{BiBLIOGRAFÍA CITADA}

BANFI DEL Río, Cristián (2012). "Por una reparación integral del daño extracontractual limitada a los hechos dolosos o gravemente negligentes". Ius et Praxis, Vol. 18, No 2, pp. 3-32.

BANFI DEL Río, Cristián (2013). "La responsabilidad civil como forma de aplicación privada del derecho de la competencia". Revista Chilena de Derecho Privado, No 21, pp. 225-231.

Barros Bourie, Enrique (2006). Tratado de Responsabilidad Extracontractual. Santiago: Editorial Jurídica de Chile.

BeEver, Allan (2003). “The Structure of Aggravated and Exemplary Damages". Oxford Journal of Legal Studies, Vol. 23, No 1, pp. 87-110.

Birks, Peter (1992). "Civil Wrongs: A New World”. En: Buttersworths Lectures 1990-1991, London: Buttersworths, pp. 55-112.

Coderch, Pablo Salvador y Castiñeira Palou, María Teresa (1997). Prevenir y Castigar. Libertad de información, expresión, tutela del honor y funciones del derecho de daños. Madrid: Marcial Pons.

Coleman, Jules L. (2010). Riesgos y Daños. Papayannis, Diego M. (Trad.), Madrid: Marcial Pons.

Corral Talciani, Hernán (2013). Lecciones de Responsabilidad Extracontractual, Santiago: Thomson Reuters, 2a Edición actualizada.

De Ángel Yágüez, Ricardo (2012). Daños Punitivos. Madrid: Civitas.

Domínguez Hidalgo, Carmen (2008). "Los derechos de la personalidad y el principio de reparación integral del daño". En: Estudios de Derecho Civil IV. Jornadas Nacionales de Derecho Civil, Olmué, Pizarro Wilson, Carlos (Coord.), Santiago: LegalPublishing, pp. 645-659.

Edelman, James (2009). "In Defence of Exemplary Damages". En: Justifying Private Law Remedies, Rickett, Charles E.F. (Ed.), Oxford: Hart Publishing, pp. 226-248.

GoldberG, John C.P. y Zipursky, Benjamin C. (2014). “Tort Law and Responsibility". En: Philosophical Foundations of the Law of Torts, OBERDIEK, John (Ed.), Oxford: Oxford University Press, pp. 17-37.

Gómez Tomillo, Manuel (2013). "Los daños punitivos: Análisis desde una perspectiva jurídico-penal. Al mismo tiempo reflexión sobre garantías en fenómenos materialmente sancionatorios". En: Limites entre el Derecho Sancionador y el 
Derecho Privado: Daños Punitivos, comiso y responsabilidad patrimonial derivada de infracciones administrativas, Gómez Tomillo, Manuel (Ed.), Madrid: Lex Nova, pp. 33-51.

Hart, H.L.A. (1963). El Concepto de Derecho [The Concept of Law]. Carrió, Genaro R. (Trad.), Buenos Aires: Abeledo Perrot.

Honoré, Tony (1999). Responsibility and Fault. Oxford \& Portland: Hart Publishing.

Larraín PÁez, Cristián (2008). "Aproximación a los Punitive Damages". En: Estudios de Derecho Civil IV. Jornadas Nacionales de Derecho Civil, Olmué, PIZARro Wilson, Carlos (Coord.), Santiago: LegalPublishing, pp. 707-719.

Papayannis, Diego M. (2014). Comprensión y Justificación de la Responsabilidad Extracontractual. Madrid: Marcial Pons.

Pereira Fredes, Esteban (2014). "Reglas primarias y teoría analítica del derecho". En: Hart en la Teoría del Derecho Contemporánea: A 50 años de El Concepto de Derecho, Figueroa Rubio, Sebastián (Ed.), Santiago: Ediciones Universidad Diego Portales, pp. 391-402.

Pino-EMHART, Alberto (2013). "Entre reparación y distribución: La responsabilidad civil extracontractual como mecanismo de distribución de infortunios". Revista Chilena de Derecho Privado, No 21, pp. 89-135.

Pizarro, Ramón Daniel (1996). Daño moral. Prevención. Reparación. Punición. El daño moral en las diversas ramas del Derecho. Buenos Aires: Hammurabi.

SeboK, Anthony J. (2007). "Punitive Damages: From Myth to Theory". Iowa Law Review, No 92, pp. 957-1036.

Segura Rivero, Francisco (2005). "Algunas consideraciones sobre la pena privada y los daños punitivos en el derecho civil chileno”. En: Estudios de Derecho Civil. Jornadas Nacionales de Derecho Civil 2005-2009, Tomo IV, VAras Braun, Juan Andrés et al. (Coords.), Santiago: Abeledo Perrot, pp. 89-103.

TAN, Yock Lin (2009). "Deterrence in Private Law". En: The Goals of Private Law, Robertson, Andrew y Tang, Hang Wu (Eds.), Oxford \& Portland: Hart Publishing, pp. 311-339.

WeInRIB, Ernest J. (2012). The Idea of Private Law. Oxford: Oxford University Press, 2a Edición revisada.

\section{JURISPRUDENCIA CITADA}

Corte de Apelaciones de Talca, "Warnken Díaz con Fisco de Chile", 10 de enero de 2010 (indemnización de perjuicios), rol No 1356-2008.

Corte de Apelaciones de Concepción, "Sanhueza Vega con Vallejos Godoy", 12 de marzo de 2013 (indemnización de perjuicios), rol No 1098-2012.

Corte de Apelaciones de Rancagua, "Arancibia More con Comercial Eccsa S.A.", 1 de julio de 2013 (indemnización de perjuicios), rol No 1726-2012. 
Corte de Apelaciones de Rancagua, "Juacida Percaz con Pizarro Letelier", 19 de mayo de 2014 (indemnización de perjuicios), rol No 1119-2013.

\section{NORMAS CITADAS}

Código Civil.

Ley No 19.496, establece normas sobre protección de los derechos de los consumidores, Diario Oficial, 7 de marzo de 1997.

Ley No 19.628, sobre protección de la vida privada, Diario Oficial, 28 de agosto de 1999.

Ley No 26.361, modificación a la ley No 24.240 de defensa del consumidor, Argentina, 3 de abril de 2008 . 